Научная статья

УДК $316.32+008.001$

DOI: $10.18101 / 1994-0866-2021-1-11-18$

\title{
СОЦИОКУЛЬТУРНЫЕ И ИСТОРИКО-ИДЕОЛОГИЧЕСКИЕ ИСТОКИ ВАРВАРИЗАЦИИ ОТЕЧЕСТВЕННОЙ КУЛЬТУРЫ
}

\author{
(C) Гизитдинова Альбина Айдаровна \\ аспирант, \\ Башкирский государственный университет \\ Россия, 450095, г. Уфа, ул. Заки Валиди, 36 \\ argen-berg@mail.ru
}

\begin{abstract}
Аннотация. В статье рассматриваются социокультурные и историкоидеологические предпосылки формирования основ культурного взаимодействия и социокультурных процессов в современном российском обществе, что включает в широком смысле межличностные, межнациональные и межконфессиональные отношения, отечественную социокультурную традицию. Приведены радикальные исторические преобразования, оказавшие значительное влияние на национальную память, на личностное и общественное сознание. По мнению автора, масштабная мировоззренческая переориентация общественного сознания в истории российского государства происходила под воздействием радикальных социокультурных реформ императора Петра I, Октябрьской революции 1917 г., большевизма и тоталитарного режима в стране, унификации культуры и образа жизни в советском государстве, агрессивной антирелигиозной пропаганды, а также разрыва с собственной социокультурной традицией и некритического копирования западного опыта в период перестройки.

Ключевые слова: историческая и культурная память народа; социокультурные процессы; межкультурные коммуникации; цивилизационное развитие; традиционные ценности; варваризация культуры.
\end{abstract}

\section{Для цитирования}

Гизитдинова А. А. Социокультурные и историко-идеологические истоки варваризации отечественной культуры // Вестник Бурятского государственного университета. Философия. 2021. Вып. 1. С. 11-18.

Исторические процессы (и позитивные, и негативные) в отечественной социокультуре затрагивали и затрагивают в широком смысле межличностные, межнациональные и межконфессиональные отношения, формируют особенности отечественной культуры, отношение общества к языку, традициям, религии, культурной памяти. Понятие культурной памяти тесно связано с социокультурными особенностями развития общества. Культурную память можно характеризовать как «имманентное свойство социокультурного организма (общества), состоящее в его способности сохранять себя во всех своих модификациях, воспроизводя условия своего собственного существования на всех этапах развития» [8]. Являясь социальной, по сути, и выступая, по мнению Т. Э. Рагозиной, «в качестве сохранения и передачи социально значимого опыта», культурная память 
играет важную роль в формировании культурных процессов современной России, выступает важным внутренним детерминантом.

Любое радикальное историческое преобразование, тем более социальная и культурная революция, оказывает значительное влияние на национальную память, на личностное и общественное сознание, меняя его приоритеты, установки и ценностные ориентации. Справедливо утверждение Ю. Ю. Булычева о формировании общественного сознания: «именно мировоззренческий сдвиг общественного сознания в сторону от традиционных ценностей делает возможным принципиальное изменение типа общественной жизни, отражение назревших цивилизационных потребностей и общественных противоречий в форме принудительной модернизации или социального переворота, отрекающихся от прошлого» $[1$, c. 83$]$.

Масштабная мировоззренческая переориентация общественного сознания в истории российского государства произошла под воздействием радикальных социокультурных реформ императора Петра I, который, «прорубив окно в Европу», стал подвижником идеи тотальной модернизации российского общества и традиционной социокультуры.

Данные преобразования ставили ясную цивилизационную цель: «повысить динамику русского бытия, превратить чересчур консервативную Россию в мощный и подвижный корабль, вывести ее на простор всемирной истории и международных коммуникаций» [1, с. 90]. Целенаправленно и стремительно менялись в первую очередь консервативное миропонимание и мироотношение традиционного человека. Вводились новые правила и нормы личностного и социального бытия, не соблюдать которые не представлялось возможным.

Своей «социокультурной революцией» Петр I хотел вывести российское общество на совершенно новый уровень развития, ориентируясь на ценности западной культуры, где-то жертвуя национальными обычаями и не задумываясь о том, что подобная модернизация отечественной культуры размывает уникальный «неевропейский» культурный мир, который имеет свое ментальное понимание христианской веры, свою собственную, обусловленную духовной и исторической биографией государственную идею, свой собственный неповторимый исторический путь.

Следует отметить, что некоторые исследователи считают, что внутреннее расшатывание отечественной социокультуры началось еще до радикальных социокультурных реформ Петра I: «стремительное развитие Западной Европы по пути секуляризации и индустриализации порождало необходимость и для России цивилизационного усовершенствования. Чувство необходимости обновления страны, установка на полноправное вхождение ее в мир земной истории укоренялись в правящем слое уже в московский период» [1, с. 90]. Если подобное переосмысление настоящего и будущего Российского государства уходит корнями еще в допетровскую Россию, то Петр I продолжил этот судьбоносный процесс приобщения к западноевропейскому миру уже более радикальными методами.

Безусловно, постепенный выход в мир международных коммуникаций, встреча с иными социокультурными ценностями во многом способствовали тому, 
что Россия одновременно утрачивала определенные традиционные ценностные ориентации, исконные характеристики национальной идентичности и архетипические смыслы самобытной культуры, особенно среди представителей высших сословий и культурной элиты. Модернизация отечественной социокультуры в период правления Петра I носила характер некритического копирования западноевропейской культуры.

В дальнейшем еще не раз отечественная социокультура периодически будет совершать подобные цивилизационные прорывы в сторону Запада. Как подчеркивал А. Тойнби, «русские на протяжении примерно тысячелетия принадлежали к византийской цивилизации, а затем совершили два мощных рывка в сторону Запада - усилиями Петра I и большевиков» [12, с. 106]. Приверженцами данной точки зрения являются многие исследователи, рассматривающие «цивилизационное развитие России как "метание" между Востоком и Западом» (А. С. Ахиезер) $[3$, c. 16].

Как известно, осмысление личностных и общественных последствий петровской социокультурной модернизации, их влияния на массовое сознание, на культурное мышление и национальный дух началось еще в XIX в. западниками и славянофилами. В частности, А. А. Кара-Мурза достаточно категоричен в своих суждениях, отмечая, что «в своей полемике западничество и славянофильство субъективно опознают оппонента не как конкурента в деле культурноцивилизационного выстраивания России, а именно как главного виновника ее варваризации. Западники считают «самобытничество» упорствованием в диком, недоцивилизованном прозябании; славянофилы же, в свою очередь, обвиняют западников в намеренном лишении российской цивилизации ее идентичности» $[5$, c. 90]. Подчеркивая неблагоприятный исход противостояния между западниками и славянофилами, А. А. Кара-Мурза отмечает, что «всякий раз получаем варваризацию, т. е. несомненное одичание, причем в формах, которых не желали ни западники, ни славянофилы» [5, с. 90]. Варваризацию в данном контексте следует понимать как «внутреннее варварство», «социальную деградацию» (А. А. Кара-Мурза), подразумевающую самоуничтожение собственной социокультуры.

Отсутствие взаимопонимания в дискуссии западников и славянофилов, безусловно, оказало влияние на мировоззрение и миропонимание индивида, в социокультуре происходит мировоззренческий сдвиг общественного сознания, начали возникать сомнения в «правильности» и ценности своей традиционной культуры, религии и веры, традиций и устройства быта.

Следующий этап в отечественной социокультурной истории, оказавший существенное влияние на массовое сознание и культурную память, - это Октябрьская революция 1917 г., большевизм и тоталитарный режим в стране, кардинально изменившие цивилизационную траекторию развития российской социокультуры. После революционных трансформаций многие жизненные смыслы, ценности и социальные устои общества подверглись сознательному и целенаправленному разрушению. С. Л. Данильченко, в частности, указывает на образование новой гражданской нации без различия национальностей: «В результате индустриализации, урбанизации, массовых миграций, утверждения атеизма и т. д. 
началось стирание межнациональных различий народов Советского Союза, особенно в среде городского населения. Унификация культуры и образа жизни, а также формальное уравнение всех граждан перед законом без различий национальностей создали необходимые предпосылки для формирования единой цивилизационой общности» [3, с. 20]. Попытка искусственного форматирования социокультуры и нивелирование национальных различий в целях создания «безликого» общества без национальностей чуть не привела к катастрофе. Марксистско-ленинская идеология, переосмысленная в контексте большевистской, не учитывала историческую и культурную специфику регионов, вероисповедание и традиции и способствовала внутренней варваризации культуры, особенно ее этнической ипостаси. А. А. Кара-Мурза, в частности, отметил, что «коммунистический режим предложил варварский способ борьбы против варварства» [7, с. 61], подтвердив опасения С. Л. Франка, что «большевистский коммунизм» явился очередным на Руси по-русски безоглядным «тотальным отречением от истории» и верой в светлое советское будущее «на опустошенной земле» $[4$, с. 6]. Кризис традиционной цивилизации затронул все сферы отечественной социокультуры, ее ценности, особенно пострадал религиозный мир: и православный, и мусульманский.

В частности, в национальных республиках (таких как, например, Татарстан и Башкортостан) господствовала агрессивная антирелигиозная пропаганда. Ислам был объявлен «религией феодалов», «орудием угнетения трудящихся масс», это положило начало преследованию многих религиозных и общественных деятелей [2, с. 94]. Разрушались мусульманские институты образования, духовенства, религиозные организации, велась активная антирелигиозная работа в публицистике, выходили в печать агитационно-пропагандистские издания.

Известны попытки мусульманских богословов защитить в сложившихся условиях религию, которые описывает исследователь исламской культуры А. К. Бустанов. Он и приводит в пример труд Ф. Бабича, составленный в 1969 г.: «Главный посыл труда Бабича: ислам не противоречит коммунистической идеологии и прогрессивной науке, а, напротив, является фундаментом идеального социального устройства. В этом смысле Бабич выступал в защиту сотрудничества советского проекта модернизации и исламской традиции, но эти идеи остались маргинальными, поскольку его книга не была опубликована» [2, с. 97-98]. Несмотря на в целом положительные и конструктивные достижения в создании социального государства, к сожалению, одновременно разрушались его многие духовные и культурные основы: религия, традиционные архетипы, этническая идентичность и др.

Оттепель как либерализация духовно-политической, идеологической и культурной жизни стала новой страницей в отечественной социокультурной истории. В частности, творческий мир переживал позитивные перемены: уже в начале 1950-х гг. писатели начинают поднимать темы о роли интеллигенции в отечественной социокультуре, о мировоззренческом, духовном и культурологическом потенциале для массового сознания художественного начала. 
Ряд авторов начинает отходить от господствующих в искусстве принципов социалистического реализма и пробует новые формы творчества. Большое влияние не только на художественное мировоззрение, но и на массовое сознание оказывает так называемое приоткрытие железного занавеса, когда в культурной жизни начинают проходить выставки иностранных художников, открываются другие миры, растет культурный обмен между государствами, расширяется международное общение, происходит смягчение цензуры. 25 июля 1959 г. была открыта первая в истории СССР американская национальная выставка, в стране впервые показали «Собор» Джексона Поллока и «Старое золото над белым» Марка Ротко. Появилось такое направление, как нонконформизм - обозначение представителей различных художественных течений в изобразительном искусстве в Советском Союзе 1950-1980-х гг., взгляды которых противоречили установкам социалистического реализма - официально разрешенного направления для творчества. Тем не менее очередным фактом «дальнейшей варваризации» отечественной социокультуры, в частности ее художественной ипостаси, стали посещение 1 декабря 1962 г. Н. С. Хрущевым выставки в Манеже, приуроченной к 30-летию Московского отделения Союза художников, на которой демонстрировались работы советских абстракционистов и сюрреалистов, и его реакция, которую можно свести к следующему утверждению - «такое искусство советскому народу не нужно». Подобные запреты на свободную художественную жизнь способствовали угасанию творческого начала, массовому отъезду художников и писателей: массовое сознание, в свою очередь, воспринимало это как сигнал, что за границей культурная жизнь более свободна и открыта, что способствовало рождению в обществе западных умонастроений и интереса к «фаустовской культуре».

Среди критически настроенных в отношении советской социокультуры особенно выделялась интеллигенция. Научные сотрудники, писатели, художники, кинематографисты, студенты, общественные деятели принимали участие в дискуссиях по поводу экономических, политических и духовных проблем в стране, обсуждая судьбу отечественной культуры. Д. С. Сазанов, в частности, выделяет три основные идейные группы: идеи первой группы были ориентированы на рыночную экономику, так называемая либеральная группа видела развитие страны в переходе к демократии; представители второй консервативной группы были сторонниками сохранения социализма в Советском Союзе; третья идейная группа «почвенничество» выступала за отказ от советского режима, в то же время была против либеральной (западной) модели развития, представители «почвенничества» ориентировались на возвращение к модели дореволюционной России $[11$, c. 155$]$.

Не только интеллигенция и общественные деятели, но и все общественное сознание искало причины системного кризиса и варваризации отечественной социокультуры в идеологии социалистического строя. «Перестройка», начавшийся разрыв с собственной социокультурной традицией, «некритическое копирование западного опыта, пропагандируемое сторонниками либеральной идеологии, навязывание российскому обществу западных ценностей без учета собственных 
культурных норм и смыслов сделали очень многое для разрушения отечественной духовности и нравственности, привели к росту протеста со стороны защитников традиционных взглядов и социальных норм» [10]. По мнению «почвенников», ответственность за ошибки в политике М. С. Горбачева несут представители либеральных идей и сторонники рыночных преобразований страны.

Среди причин очередного отечественного культурного кризиса, начавшегося в первой половине 1990-х, - разрушение диалектики традиций и новаций, тотальный отказ от многих положительных достижений в прошлом страны, европеизация без учета национальной специфики российской социокультуры и менталитета. В очередной раз произошла модернизация финансовой идеологии, которая стремилась активизировать социальные факторы экономического роста без учета фактора самосознания народа и его особенностей [6, с. 176-177].

После распада многонационального советского общества перед образовавшимися на постсоветском пространстве государствами возник целый комплекс социокультурных проблем и задач, многие из которых до сих пор не решены. Современная Россия также столкнулась с идентификационными затруднениями из-за многочисленных социокультурных перипетий в своей цивилизационной биографии. На протяжении длительного исторического времени, начиная с преобразований Петра I, страна меняла свои национальные идеи и общепризнанные символы, которые идентифицировали Россию как единую нацию и единое цивилизационное и социокультурное целое. В каком- то смысле терялась идея обособленности культуры, которая необходима для сохранения своей культурной идентичности. Более того, перед отечественной культурой сегодня стоит реальная угроза потери самобытности, уникальности, растворения в унифицированных ценностях глобальной культуры. Справедливо утверждение 3. Я. Рахматуллиной о том, что «состояние современной отечественной социокультуры это результат многочисленных вызовов, обусловленных как внешними, геополитическими причинами, так и собственными, внутренними проблемами. «Европейничанье», длительное обесценивание таких глубинных культурных ценностей, как патриотизм, гражданственность, уважение к собственной истории, родному языку и др., составляющих духовную матрицу отечественной социокультурной традиции, вместе с социально-экономическими и духовно-нравственными проблемами в жизни современного российского общества в конечном итоге поставили под серьезную угрозу национальную безопасность страны и национальное спокойствие граждан» [9, с. 13].

Сегодня, в условиях наступающей глобализации, многонациональная и многоконфессиональная Россия как самобытная ипостась мирового культурного мира нуждается в сохранении и качественном развитии национальной культуры. Диалог культур в эпоху ускоренных социокультурных процессов и информационной открытости должен осуществляться при условии целенаправленной и системной экологии отечественной культуры и на личностном, и на социальном, и на государственном уровне. 
Лuтература

1. Булычев Ю. Ю. Природа и история в русской культуре // Вестник русской христианской гуманитарной академии. СПб., 2006. Т. 7, вып. 2. С. 83.

2. Бустанов А. Коран для советских граждан: риторика прогресса в богословских трудах Габделбари Исаева // Антропологический форум. 2018. № 37. С. 93-110.

3. Данильченко С. Л. Сущность русской цивилизации: к вопросу о традиционных ценностях и историческом развитии России // Образование и наука: современные тренды: коллективная монография (Чебоксары, 31 дек. 2016 г.) / гл. ред. О. Н. Широков. Чебоксары: ЦНС «Интерактив плюс», 2016. С. 2-28.

4. Кара-Мурза А. А., Панарин А. С., Пантин И. К. Духовно-идеологическая ситуация в современной России: перспективы развития // Полис. Политические исследования. 1995. № 4. С. 6.

5. Кара-Мурза А. А. Что такое российское западничество? (Размышления участника конференции). Полис. Политические исследования. 1993. № 2. С. 90.

6. Кондратьев Н. Д. Основные проблемы экономической статики и динамики. М., 1991. С. $176-177$.

7. Листовская В. Н., Кара-Мурза А. А. Как возможна Россия?: статьи и выступления разных лет / Фонд социал.-экон. исслед. «Преобразование-2000» и др. М., 1999. 224 с.

8. Рагозина Т. Э. Культурная память versus историческая память // Наука. Искусство. Культура. 2017. № 3(15). URL: https://cyberleninka.ru/article/n/kulturnaya-pamyatversus-istoricheskaya-pamyat (дата обращения: 06.11.2020). Текст: электронный.

9. Рахматуллина 3. Я., Бондаренко А. В., Лукиянов М. Ю. Мир держится на культуpe // Евразийский юридический журнал. 2019. № 12(139). С. 12-21.

10. Сазанов Д. С. Критика западного пути развития в журналах «почвеннической» направленности в эпоху перестройки // Современные исследования социальных проблем (электронный журнал). 2011. № 3(07). URL: http://sisp.nkras.ru/issues/2011/3/sazonov.pdf (дата обращения: 17.11.2020). Текст: электронный

11. Сазанов Д. С. Советская интеллигенция в условиях перестройки: трансформация ценностных ориентаций // Вектор науки Тольяттинского государственного университета. 2011. № 4. С. 154-157.

12. Тойнби А. Цивилизация перед судом истории. М., СПб., 1996. С. 106.

Статья поступила в редакиию 17.11.2020; одобрена после рецензирования 23.01.2021; принята к публикации 09.02.2021.

\title{
SOCIOCULTURAL, HISTORICAL AND IDEOLOGICAL ORIGINS \\ OF THE BARBARIZATION OF RUSSIAN CULTURE
}

\author{
Albina A. Gizitdinova \\ Research Assistant, \\ Bashkir State University \\ 36 Zaki Validi St., Ufa 450095, Russia \\ argen-berg@mail.ru
}

Abstract. The article deals with the sociocultural, historical and ideological background for the development of the basic principles of cultural interaction and communication. We have analyzed socio-cultural processes in modern Russian society, which includes interpersonal, interethnic and interfaith communication, sociocultural tradition. The article dis- 
cusses revolutionary changes that had a significant impact on national memory, personal and social consciousness. In our opinion, the global world outlook reorientation of public consciousness in the history of the Russian state took place under the influence of the sweeping socio-cultural reforms of Emperor Peter I, the October Revolution of 1917, bolshevism and the totalitarian rule, the unification of culture and lifestyle in the Soviet state, aggressive anti-religious propaganda, as well as break from sociocultural tradition and uncritical copying of Western experience in "perestroika".

Keywords: historical and cultural memory of the people; sociocultural processes; intercultural communication; civilizational development; traditional values; barbarization of culture.

\section{For citation}

Gizitdinova A. A. Sociocultural, Historical and Ideological Origins of the Barbarization of Russian Culture: A Historiosophical Analysis. Bulletin of Buryat State University. Philisophy. 2021; 1: 11-18 (In Russ.).

The article was submitted 17.11.2021; approved after reviewing 23.01.2021; accepted for publication 09.02.2021. 